\title{
The effect of mirtazapine on methotrexate-induced oxidative damage and infertility in rats
}

\author{
Omer Erkan Yapca ${ }^{\mathrm{a}}$, Bunyamin Borekci ${ }^{\mathrm{b}}$, Mehmet Ibrahim Turan ${ }^{\mathrm{c}, *}$, Mine Gulapoglu ${ }^{\mathrm{d}}$, \\ Suleyman Salman ${ }^{\mathrm{e}}$ \\ a Sorgun State Hospital, Obstetric and Gynecology, Yozgat, Turkey \\ b Ataturk University, Department of Obstetric and Gynecology, Erzurum, Turkey \\ c Research and Educational Hospital, Department of Pediatric Neurology, Diyarbakir, Turkey \\ d Ataturk University, Department of Biochemistry, Erzurum, Turkey \\ e Taksim Research and Educational Hospital, İstanbul, Turkey \\ *Corresponding author, e-mail: turan78tr@hotmail.com
}

\begin{abstract}
Methotrexate (MTX) is a folic acid antagonist and common chemotherapeutic drug. This study investigated the effectiveness of mirtazapine in preventing infertility developed by MTX-associated oxidative damage. In addition, we demonstrate an association between oxidative stress in ovarian tissue induced by MTX and infertility. Rats were divided into three groups: MTX control, mirtazapine + MTX, and healthy control. At the end of the procedures the reproductive function was noted and ovaries extracted to determine malondialdehyde (MDA), myeloperoxidase (MPO), and total glutathione (GSH) levels. MDA concentration in ovarian tissue in the control group given MTX was $13.7 \pm 2.1 \mu \mathrm{mol} / \mathrm{g}$ protein. In the mirtazapine + MTX group and healthy control group the levels were $7.5 \pm 1.9$ and $4.0 \pm 1.4 \mu \mathrm{mol} / \mathrm{g}$ protein, respectively. MPO activity in the control group given MTX, mirtazapine + MTX, and healthy control groups was 17.8 $\pm 4.7,7.5 \pm 2.4$, and $5.2 \pm 1.7 \mu \mathrm{mol} / \mathrm{g}$ protein, and GSH levels $4.5 \pm 2.1,11.8 \pm 3.9$, and $14.7 \pm 4.7 \mathrm{nmol} / \mathrm{g}$ protein, respectively. The study also demonstrated an association between oxidative stress induced by MTX in ovarian tissue and infertility. The mirtazapine used prevented MTX-associated infertility. There were no live births in the control group given MTX alone. However, only one of the 10 rats kept for reproduction did not give birth in the mirtazapine + MTX (end of the procedure only given mirtazapine) group. In conclusion, mirtazapine can be used to prevent infertility appearing in patients receiving MTX therapy.
\end{abstract}

KEYWORDS: antineoplastic agents, animals, reproduction, chemotherapy

\section{INTRODUCTION}

Long-term use of chemotherapeutic agents during the treatment of cancer in childhood and the reproductive period can lead to various complications, such as ovarian insufficiency and infertility ${ }^{1}$. A search for methods to prevent infertility in patients receiving chemotherapy is becoming increasingly important ${ }^{2}$. Methotrexate (MTX) is a folic acid antagonist and chemotherapeutic agent frequently used in haematological malignities, such as lymphoblastic leukaemia, seen in childhood and adulthood ${ }^{3}$.

Due to its immunosuppressive and antimetabolite effects, it is also effective in autoimmune diseases, such as rheumatoid arthritis and psoriasis ${ }^{4}$. MTX exerts its effects by reversible inhibition of the enzyme dihydrofolate reductase ${ }^{5}$, resulting in decreasing folate synthesis, impairing DNA synthesis, and cell multiplication. Toxicity is therefore more pronounced in cells with a rapid turnover ${ }^{5}$. MTX has previously been shown to cause ovarian dysfunction, particularly in high doses ${ }^{6}$. MTX is associated with a decrease in ovarian primordial cells, although the mechanism and long-term effects have not been established ${ }^{7}$. Since primordial follicles lack the ability to regenerate, damage resulting from exposure to toxic agents can lead to ovarian insufficiency and infertility ${ }^{8}$. This information from the literature suggests that MTXassociated side-effects generally stem from its folate antagonizing property. Although these undesirable effects of MTX might theoretically be reduced or prevented by a treatment with folic acid, there is still no consensus on the subject. On the contrary, there are studies showing that the effectiveness of MTX decreases with the addition of folic acid to MTX therapy ${ }^{9}$. This shows that the toxic effect of MTX has not yet been fully clarified. MTX has been reported to increase lipid peroxidation and reduce antioxidant 
activity in various organs, thus explaining its toxic mechanism $^{10-12}$.

The mirtazapine tested in this study is an antidepressant used in the treatment of major depression. In addition to its antidepressant effect, mirtazapine also posses antioxidant properties and has been reported to be a cell protecting agent. Our search of the literature reveals no information about infertility appearing in rats with oxidative damage induced with MTX being prevented by mirtazapine. The purpose of this study was therefore to investigate whether mirtazapine is effective in preventing infertility in rats with oxidative damage induced with MTX and to show an association between oxidative stress in ovarian tissue and infertility.

\section{MATERIALS AND METHODS}

\section{Animals}

Fifty-eight female albino Wistar rats weighing 160 $175 \mathrm{~g}$ were used. These were obtained from the Ataturk University Medical Experimental Practice and Research Centre, Turkey, and kept in groups at normal room temperature $\left(22^{\circ} \mathrm{C}\right)$. All studies were performed in accordance with the ethical guidelines set by the local ethical committee that were fully compatible with the "NIH Guide for the Care and use of laboratory animals" (02.12.2011/11-90).

\section{Chemicals}

The thiopental sodium used in the experiment was obtained from IE Ulagay-Turkey, MTX from LibaTurkey and mirtazapine from Organon Pharmaceuticals, NJ, USA.

\section{Mirtazapine treatment}

The rats to be used in this experimental series were randomly divided without an intervention into three groups: MTX control (MTXC), mirtazapine + MTX (MMTX), and healthy (HG). Rats in the MTXC group $(n=6)$ were injected with $2 \mathrm{mg} / \mathrm{kg}$ MTX by the intraperitoneal (i.p.) route. In the MMTX group $(n=6), 1 \mathrm{~h}$ after the oral administration of $20 \mathrm{mg} / \mathrm{kg}$ mirtazapine, $2 \mathrm{mg} / \mathrm{kg}$ MTX was administered i.p. The HG group ( $n=6$ ) was given an equivalent volume of distilled water as solvent by the oral route. This procedure was performed for one month. At the end of that period, all rats were sacrificed with an overdose of anaesthesia (50 mg/ $\mathrm{kg}$ thiopental), the ovaries extracted and malondialdehyde (MDA), myeloperoxidase (MPO), and total glutathione (GSH) levels in ovarian tissue measured.

\section{Reproductive function}

Rats used in this series in the experiment were divided into four groups: a control group given MTX alone (MCG), a group given mirtazapine + MTX (MMG1), a group given mirtazapine + MTX (MMG2), and a healthy control group (HG). The MCG group $(n=10)$ was injected i.p. with MTX at a dose of $2 \mathrm{mg} / \mathrm{kg}$, while MMG1 and MMG2 group rats were given mirtazapine at $20 \mathrm{mg} / \mathrm{kg}$ by oral route, followed by MTX at $2 \mathrm{mg} / \mathrm{kg}$ i.p. The HG group was given distilled water as solvent instead of MTX by i.p. route. These procedures were applied for one month. At the end of that period, MTX and mirtazapine were stopped in the MCG and MMG1 groups and MTX alone was stopped in the MMG2 group. After MTX had been stopped in the MMG2 group, mirtazapine continued to be given for one month. At the end of that period, all animal groups (MCG, MMG1, MMG2 and HG) were kept for 6 months in appropriate laboratory conditions to reproduce. Rats that did not become pregnant and give birth during that time were regarded as infertile.

\section{Biochemical analysis of ovarian tissue}

At this stage, extracted ovarian tissues of weight $0.2 \mathrm{~g}$ each were homogenized in $0.5 \%$ HDTMAB $(0.5 \%$ hexadecylthrimethylammonium bromide) containing $\mathrm{pH}=6 \mathrm{~K}_{3} \mathrm{PO}_{4}$ buffer for MPO assay, $1 \% \mathrm{KCl}$ solution for MDA assay or $\mathrm{pH}=7.5$ phosphate buffer for other measurements, all made up to $2 \mathrm{ml}$ in an iced environment. They were subsequently centrifuged at $15320 \mathrm{~g}$ for $15 \mathrm{~min}$ at $+4{ }^{\circ} \mathrm{C}$. The supernatant part was used as a specimen for analysis. All measurements of tissue-protein estimation were performed according to Bradford's method ${ }^{13}$.

Malondialdehyde (MDA) assay was based on spectrophotometric measurements at an emission wavelength of $532 \mathrm{~nm}$ of the absorbance of the pink complex formed at high temperature $\left(95^{\circ} \mathrm{C}\right)$ by thiobarbituric acid and $\mathrm{MDA}^{14}$. Myeloperoxidase (MPO) activity assay consisted of the oxidation reaction performed with MPO-mediated $\mathrm{H}_{2} \mathrm{O}_{2}$ containing 4-aminoantipyrene/phenol solution as substrate $^{15}$. Total glutathione (tGSH) assay uses DTNB [5,5'-dithiobis (2-nitrobenzoic acid)], a disulphide chromogen easily reduced by sulphhydryl group compounds. The resulting yellow colour is measured spectrophotometrically at $412 \mathrm{~nm}^{16}$.

\section{Statistical analysis}

All data were subjected to one-way ANOVA using Statistical Package for Social Sciences 18.0 (Armonk, 


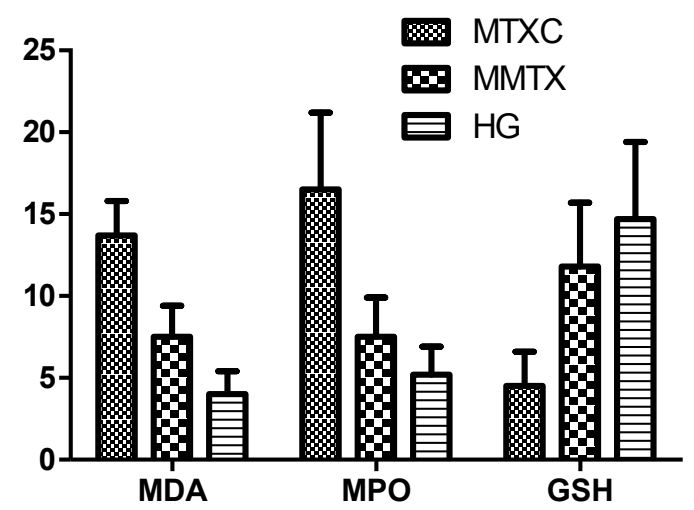

Fig. 1 Comparison of the MDA, MPO, and GSH levels among the groups. MCG, control group given methotrexate alone; MMTX, mirtazapine + methotrexate; HG, healthy group. Bars are mean \pm standard deviation. MDA levels defined in $\mu \mathrm{mol} / \mathrm{g}$ protein, MPO levels defined in $\mu \mathrm{mol} / \mathrm{g}$ protein, GSH levels defined in $\mathrm{nmol} / \mathrm{g}$ protein.

NY, USA) software. Differences among groups were obtained using the least significant difference option and significance was declared at $p \leqslant 0.01$. The results are reported as mean \pm standard deviation.

\section{RESULTS}

\section{Oxidative stress test in ovarian tissue}

This part of the experiment investigated the effect of mirtazapine on MDA, MPO, and GSH levels in ovarian tissue in rats given MTX. Mean MDA levels in the MTXC, MMTX, and HG group rat ovarian tissues were $13.7 \pm 2.1,7.5 \pm 1.9(p<0.01)$, and $4.0 \pm 1.4 \mu \mathrm{mol} / \mathrm{g}$ protein $(p<0.01)$, respectively. Mean MPO activity was $16.5 \pm 4.7,7.5 \pm 2.4$ $(p<0.01)$, and $5.2 \pm 1.7 \mu \mathrm{mol} / \mathrm{g}$ protein $(p<0.01)$, respectively. GSH levels in MTXC, MMTX, and HG rat ovarian tissue were $4.5 \pm 2.1,11.8 \pm 3.9$ $(p<0.01)$, and $14.7 \pm 4.7 \mathrm{nmol} / \mathrm{g}$ protein $(p<0.01)$, respectively (Fig. 1).

\section{Reproduction test}

The second series in our study investigated the effect of mirtazapine on reproductive dysfunctions of rats receiving MTX. The experimental results showed that 10 rats set aside for reproduction in the MCG and MMG1 groups did not give birth. In the MMG2 group, however, only one of the 10 rats kept for reproduction did not give birth. Two rats gave birth on day 120 , while the other 7 gave birth on days 128 , $130,135,139,142,145$, and 159 . The 10 rats set aside for reproduction in the HG group gave birth on days 47, 51, 53, 56, 59, 59, 61, 62, 66, and 68 (Table 1).
Table 1 Group reproduction results.

\begin{tabular}{lc}
\hline group & Infertile animals \\
\hline MCG & $10(100 \%)$ \\
MMG1 & $10(100 \%)$ \\
MMG2 & $1(10 \%)$ \\
HG & $0(0 \%)$ \\
\hline
\end{tabular}

MCG, control group given MTX alone; MMG1, mirtazapine + MTX; MMG2, mirtazapine + MTX (end of the procedure only given mirtazapine); HG, healthy group. Each group contained 10 animals.

\section{DISCUSSION}

This study investigated whether mirtazapine is effective in preventing infertility in rats with oxidative ovarian damage induced with MTX, and it showed an association between oxidative damage in ovarian tissue and infertility. The mechanism of organ toxicity of MTX seems to be oxidative stress ${ }^{17}$. Enzymatic and non-enzymatic antioxidant levels in liver, kidney, and intestinal tissue of experimental animals given MTX is suppressed, while oxidant levels rise ${ }^{18}$. MTX has been reported to increase MDA and MPO levels, the known oxidant parameters, in liver tissue and to reduce the levels of GPO, an antioxidant parameter ${ }^{19}$. As our results show, there was a rise in MDA and MPO levels in ovarian tissue in rats receiving MTX and a fall in GSH levels. These findings indicate that the oxidant/antioxidant balance in ovarian tissue in rats receiving MTX changes in favour of oxidants. Antioxidant superiority in the oxidant/antioxidant balance is not to be maintained in healthy tissues. Various aggressive factors that may lead to tissue damage can result in the oxidant/antioxidant balance being impaired in favour of oxidants and cause oxidative stress ${ }^{20}$. Data from reference sources and our results show that MTX also causes oxidative stress in ovarian tissue. The fact that MDA concentrations were higher in the MTXC group ovarian tissue than in the HG and MMTX groups reflects the severity of lipid peroxidation in the cell membrane. Lipid peroxidation is a reaction where free oxygen radicals of polyunsaturated fatty acids generate products such as peroxides, alcohols, and MDA. The MDA produced causes irreversible more severe damage in the cell membrane ${ }^{21}$.

Demiryilmaz et al reported that mirtazapine reduces MDA and MPO levels that rise with the administration of MTX and raises falling GSH levels ${ }^{22}$. This is in agreement with our results for MTX and mirtazapine. MPO activity in ovarian tissue in the MTXC group was again significantly higher compared 
to that in the HG and MMTX groups. MPO is released by activated neutrophils and is generally used as a significant inflammation marker ${ }^{23}$. Previous experimental studies on rats have reported that MTX raises the levels of MPO, a marker of neutrophil infiltration ${ }^{24}$. Free radicals cause neutrophil activation: activated neutrophils release excessive amounts of MPO in the tissue region with damage caused by free radicals ${ }^{23}$.

In this study, GSH levels in ovarian tissue in rats receiving MTX were statistically significantly lower compared to the MTXC and HG groups. GSH is an endogenous antioxidant with a tripeptide structure consisting of glutamate, cysteine, and glycine. GSH enters into reaction with peroxides and free radicals and converts them into harmless products. It protects the cells against oxidative damage caused by free radicals. In addition, GSH prevents proteins undergoing oxidative damage by binding the - $\mathrm{SH}$ groups in proteins in unreduced form ${ }^{25}$. A recent study has shown that cisplatin, which leads to infertility in rats, significantly reduces GSH levels in ovarian tissue compared to healthy subjects. That study also reported that infertility was prevented with thiamine pyrophosphate. While none of the rats kept for 6 months for reproduction in the MCG and MMG1 groups gave birth, $90 \%$ of those in the MMG2 group did so.

\section{CONCLUSIONS}

Long-term use of MTX was seen to cause oxidative damage leading to infertility in ovarian tissue. Oxidative damage caused by MTX was prevented with mirtazapine. The use of mirtazapine for some time following the discontinuation of MTX however was beneficial in preventing infertility caused by oxidative damage induced in rat ovaries with MTX. Our findings indicate that mirtazapine can be used in the prevention of infertility that may appear in patients receiving MTX therapy.

\section{REFERENCES}

1. Sonmezer M, Oktay K (2004) Fertility preservation in female patients. Hum Reprod Update 10, 251-66.

2. Oktay K, Buyuk E, Libertella N, Akar M, Rosenwaks $\mathrm{Z}$ (2005) Fertility preservation in breast cancer patients: A prospective controlled comparison of ovarian stimulation with tamoxifen and letrozole for embryo cryopreservation. J Clin Oncol 23, 4347-53.

3. de Deus DMV, de Lima ELS, Seabra Silva RM, Leite EP, Cartaxo Muniz MT (2012) Influence of methylenetetrahydrofolate reductase C677T, A1298C, and G80A polymorphisms on the survival of pediatric patients with acute lymphoblastic leukemia. Leuk Res Treat 2012, Article ID 292043, doi: 10.1155/2012/292043.
4. Prasad R, Koul V (2012) Transdermal delivery of methotrexate: Past, present and future prospects. Ther Deliv 3, 315-25.

5. Stika CS (2012) Methotrexate: The pharmacology behind medical treatment for ectopic pregnancy. Clin Obstet Gynecol 55, 433-9.

6. Shamberger RC, Sherins RJ, Ziegler JL, Glatstein E, Rosenberg SA (1981) Effects of postoperative adjuvant chemotherapy and radiotherapy on ovarian function in women undergoing treatment for soft tissue sarcoma. J Natl Canc Inst 67, 1213-8.

7. Gol M, Saygili U, Koyuncuoglu M, Uslu T (2009) Influence of high-dose methotrexate therapy on the primordial follicles of the mouse ovary. J Obstet Gynaecol Res 35, 429-33.

8. Yucebilgin MS, Terek MC, Ozsaran A, Akercan F, Zekioglu O, Isik E, Erhan Y (2004) Effect of chemotherapy on primordial follicular reserve of rat: An animal model of premature ovarian failure and infertility. Aust New Zeal J Obstet Gynaecol 44, 6-9.

9. Whittle SL, Hughes RA (2004) Folate supplementation and methotrexate treatment in rheumatoid arthritis: A review. Rheumatology 43, 267-71.

10. Vardi N, Parlakpinar H, Ates B, Cetin A, Otlu A (2013) The protective effects of prunus armeniaca 1 (apricot) against methotrexate-induced oxidative damage and apoptosis in rat kidney. J Physiol Biochem 69, 371-81.

11. Cakir T, Ozkan E, Dulundu E, Topaloglu U, Sehirli AO, Ercan F, Sener E, Sener G (2011) Caffeic acid phenethyl ester (cape) prevents methotrexate-induced hepatorenal oxidative injury in rats. $J$ Pharm Pharmacol 63, 1566-71.

12. Bauerova K, Paulovicova E, Mihalova D, Drafi F, Strosova M, Mascia C, Biasi F, Rovensky J, et al (2010) Combined methotrexate and coenzyme Q10 therapy in adjuvant-induced arthritis evaluated using parameters of inflammation and oxidative stress. Acta Biochim Pol 57, 347-54.

13. Bradford MM (1976) A rapid and sensitive method for the quantitation of microgram quantities of protein utilizing the principle of protein-dye binding. Anal Biochem 72, 248-54.

14. Ohkawa H, Ohishi N, Yagi K (1979) Assay for lipid peroxides in animal tissues by thiobarbituric acid reaction. Anal Biochem 95, 351-8.

15. Wei H, Frenkel K (1991) In vivo formation of oxidized DNA bases in tumor promoter-treated mouse skin. Canc Res 51, 4443-9.

16. Sedlak J, Lindsay RH (1968) Estimation of total, protein-bound, and nonprotein sulfhydryl groups in tissue with Ellman's reagent. Anal Biochem 25, 192-205.

17. Uraz S, Tahan V, Aygun C, Eren F, Unluguzel G, Yuksel M, Senturk O, Avsar E, et al (2008) Role of ursodeoxycholic acid in prevention of methotrexate-induced liver toxicity. Dig Dis Sci 53, 1071-7.

18. Jahovic N, Cevik H, Sehirli AO, Yegen BC, Sener G (2003) Melatonin prevents methotrexate-induced hepa- 
torenal oxidative injury in rats. J Pineal Res 34, 282-7.

19. Demiryilmaz I, Sener E, Cetin N, Altuner D, Suleyman B, Albayrak F, Akcay F, Suleyman H (2012) Biochemically and histopathologically comparative review of thiamine's and thiamine pyrophosphate's oxidative stress effects generated with methotrexate in rat liver. Med Sci Monit 18, BR475-81.

20. Kisaoglu A, Borekci B, Yapca OE, Bilen H, Suleyman H (2013) Tissue damage and oxidant/antioxidant balance. Euras J Med 45, 47-9.

21. Cighetti G, Duca L, Bortone L, Sala S, Nava I, Fiorelli G, Cappellini MD (2002) Oxidative status and malondialdehyde in beta-thalassaemia patients. Eur J Clin Investig 32, 55-60.

22. Demiryilmaz I, Uzkeser H, Cetın N, Hacimuftuoglu A, Bakan E, Altuner D (2013) Effect of mirtazapine on gastric oxidative stress and DNA injury created with methotrexate in rats. Asian J Chem 25, 2047-50.

23. Sullivan GW, Sarembock IJ, Linden J (2000) The role of inflammation in vascular diseases. J Leukoc Biol 67 , 591-602.

24. Cetinkaya A, Bulbuloglu E, Kurutas EB, Kantarceken B (2006) $\mathrm{N}$-acetylcysteine ameliorates methotrexateinduced oxidative liver damage in rats. Med Sci Monit 12, BR274-8.

25. Urso ML, Clarkson PM (2003) Oxidative stress, exercise, and antioxidant supplementation. Toxicology $\mathbf{1 8 9}$, 41-54. 